\title{
REGIÕES DE CLIMA HOMOGÊNEO NO BRASIL PARA PRODUÇÃo COMERCIAL DE OLIVEIRAS
}

WREGE, Marcos Silveira - marcos.wrege@embrapa.br

Doutor, Engenheiro Agrônomo. Embrapa Florestas/Paraná

COUTINHO, Enilton Fick - enilton@cpact.embrapa.br

Doutor, Engenheiro Agrônomo. Embrapa Clima Temperado/Rio Grande do Sul

JORGE, Rogério de Oliveira - rogerio.jorge@embrapa.br

Doutor, Engenheiro Agrônomo. Embrapa Clima Temperado/Rio Grande do Sul

FRITZSONS. Elenice - elenice.fritzsons@embrapa.br Doutora, Engenheira Agrônoma. Embrapa Florestas/Paraná

PANTANO, Angélica Prela - aprela@gmail.com

Doutora, Engenheira Agrônoma. Agência Paulista de Tecnologia dos Agronegócios, Instituto Agronômico de Campinas

\begin{abstract}
RESUMO: O objetivo deste estudo foi identificar os padrões de clima existentes nas regiões produtoras de oliveira no mundo, por meio do agrupamento em regiões climaticamente homogêneas, contribuindo, assim, para estudos de prospecção de novas zonas para produção de oliveiras no Brasil. As regiões foram agrupadas e delimitadas utilizando variáveis classificatórias definidas pelas temperaturas mínimas e máximas do ar e total de pluviosidade, calculadas para cada estação do ano. A análise possibilitou a identificação de cinco zonas homogêneas de produção de oliveiras. Uma ao norte da região mediterrânea da Europa, outra ao sul da mesma região e as demais no hemisfério sul. No mesmo agrupamento da Europa, estão algumas regiões nos Estados Unidos situadas na mesma faixa de latitude. Nos agrupamentos do hemisfério sul encontram-se as regiões do Chile, Argentina e Uruguai e, na mesma faixa de latitude, Austrália. Um dos grupos é bastante distinto de todos os demais, situando-se no Uruguai e Austrália, caracterizado por maiores volumes de pluviosidade e temperaturas mais elevadas, o que se aproxima mais das condições climáticas existentes no sul do Brasil. As cultivares usadas neste agrupamento podem ser testadas na região sul do país, com possibilidades de sucesso. Pernambuco, Bahia e Minas Gerais se aproximam mais das condições de clima do Mediterrâneo, principalmente quanto à pluviosidade, mas as temperaturas mínimas são diferentes, demonstrando a necessidade de variedades adaptadas a essas condições. O clima dos três estados tem semelhanças e cultivares usadas em Minas Gerais podem ser testadas nos outros dois estados, com chances de sucesso.
\end{abstract}

PALAVRAS-CHAVE: análise de agrupamento, análise de componentes principais, azeite de oliva, indicação de zonas para plantio, cultivo de oliveira.

REGIONS WITH CLIMATIC SIMILARITY TO COMMERCIAL CULTIVATION OF OLIVE TREE IN BRAZIL

ABSTRACT: The goal of this study was to identify weather regions patterns of olive producing in the world by means of climatic similarity and thus to contribute to prospective studies of new areas for olive production in Brazil. The regions were grouped using maximum and minimum air temperatures and annual total rainfall, calculated for each season. The analysis allowed to identify five homogeneous areas of olive production. Two of them located in Mediterranean (north and south) and another in the southern hemisphere. Belonging to Europe, at the same latitude range, there are some regions located in United States. The groups in the southern hemisphere are formed by regions of Chile, Argentina and Uruguay, and at same range of latitude, Australia. One of these groups is quite distinct from all others and it is located in Uruguay and Australia, It is 
characterized by greater volumes of rainfall and higher temperatures, which is closer to the existing climatic conditions in southern Brazil. The cultivars used in this last group can be tested in the southern region, with chances of success. The Brazilian States of Pernambuco, Bahia and Minas Gerais are closer to the climate conditions of the Mediterranean, especially regarding the rainfall, but the minimum temperatures are different, demonstrating the need for varieties adapted to these conditions. The cultivars that have being used in Minas Gerais can be used in Pernambuco and Bahia, with great chance of success.

KEYWORDS: cluster analysis, principal component analysis, olive oil, zones for planting, olive cultivation.

LAS REGIONES CON SIMILITUD CLIMÁTICA AL CULTIVO COMERCIAL DE OLIVO EN BRASIL

RESUMEN: El objetivo de este estudio fue identificar los patrones climáticos en las regiones de olivo en el mundo, a través de la agrupación en regiones climáticamente homogéneas, lo que contribuye a la investigación de estudios de nuevas áreas para la producción de olivos en Brasil. Las regiones se agruparon utilizando variables de clasificación definidos por las temperaturas del aire máximas y mínimas y precipitaciones totales, calculados para cada temporada. El análisis permitió la identificación de cinco áreas de producción homogéneas de los olivos. Uno al norte de la región mediterránea de Europa, otro al sur de la misma región y el otro en el hemisferio sur. Algunas regiones de Estados Unidos en la misma banda de latitud estaban en el mismo grupo en Europa.. En el hemisferio sur las agrupaciones son las regiones de Chile, Argentina y Uruguay, y en el mismo rango de latitud, Australia. Un grupo es muy diferente a todos los demás: Uruguay y Australia. Se caracterizan por el aumento de las precipitaciones y temperaturas y tienen condiciones climáticas similares en el sur de Brasil. Los cultivares utilizados en esta agrupación se pueden probar en la región sur, con posibilidades de éxito. Pernambuco, Bahía y Minas Gerais están más cerca de las condiciones climáticas del Mediterráneo, especialmente en cuanto a la precipitación, pero las temperaturas mínimas son diferentes, lo que demuestra la necesidad de variedades adaptadas a estas condiciones. El clima de los tres estados tienen similitudes y cultivares utilizados en Minas Gerais se pueden probar en otros dos estados, con posibilidades de éxito.

PALABRAS CLAVE: análisis de conglomerados, análisis de componentes principales, aceite de oliva, las áreas de indicación para la siembra de cultivo del olivo.

REGIONS AVEC SIMILITUDE CLIMATIQUE A LA CULTURE COMMERCIALE D'OLIVIER AU BRESIL

RÉSUMÉ: L'objectif de cette étude était d'identifier le climat des régions oléicoles dans le monde à travers de la similitude du climat et contribuer ainsi à des études de recherche de nouvelles zones pour la production d'oliviers au Brésil. Les régions ont été regroupés en utilisant les variables de classification définis par la maximale et minimale température de l'air et aussi par la précipitation annuelle totale, calculée pour chaque saison. L'analyse a permis d'identifier cinq zones homogènes de production d'olives. L'une au nord de la région méditerranéenne de l'Europe, l'autre au sud de la même région et l'autre dans l'hémisphère sud. Dans le même groupe de l'Europe, sont certaines régions des ÉtatsUnis situés dans la même gamme de latitude. Dans les groupes de l'hémisphère Sud sont les régions du Chili, l'Argentine et I'Uruguay, et sur la même ligne de latitude en Australie. Un des groupes situés en Australie et en Uruguay est très différent de tous les autres, et est caractérisé par des volumes plus importants de précipitations et des températures plus élevées, ce qui est plus proche des conditions climatiques dans le sud du Brésil. Les cultivars utilisés dans ce groupe peuvent être testés dans la région du sud avec des chances de succès. Pernambuco, Bahia et de Minas Gerais sont plus proches des conditions climatiques du groupe du Méditerranée, en particulier compte tenu de la pluie, mais les températures minimales sont différentes, ce qui démontre la nécessité pour les variétés adaptées à ces conditions. Le climat des trois Etats brésiliens ont des similitudes 
et des cultivars utilisés dans le Minas Gerais peuvent être testés dans deux autres Etats, avec de bonnes chances de succès.

MOTS-CLÉS: analyse de cluster, analyse en composantes principales, huile d'olive, les zones d'indication pour la plantation de culture de l'olivier.

\section{INTRODUÇÃO}

Nos últimos anos, o consumo do azeite de oliva tem crescido em todo o mundo, principalmente nas Américas, devido às qualidades nutricionais e organolépticas do azeite, o que aumenta a necessidade de expansão das áreas de plantio.

As áreas disponíveis para novos plantios nos países tradicionalmente produtores tem-se reduzido e, portanto, a tendência é de se buscar novas áreas com condições semelhantes às do Mediterrâneo, região em que a oliveira é tradicionalmente cultivada há séculos, ou até mesmo em zonas marginais, como as encontradas no Brasil. Nesse contexto, o sucesso da olivicultura brasileira está, em um primeiro momento, associado à escolha das cultivares mais adequadas a cada ambiente. A escolha da cultivar certa implica diretamente na qualidade do azeite de oliva, necessária para sua inserção no mercado nacional.

A oliveira é uma planta de clima mediterrâneo, com características xerofíticas, desenvolvendo-se bem inclusive em regiões com verões longos, quentes e secos, e com baixa pluviosidade. Graças às qualidades que possui, foi introduzida em quase todos os continentes. Tradicionalmente é cultivada no sul da Europa, nos países mediterrâneos, como Portugal, Espanha, França, Itália e Grécia.

A cultura se expandiu para outros países, entre os paralelos 30 e $45^{\circ}$, tanto nos hemisférios Norte e Sul, onde as características de clima são semelhantes aos países do sul da Europa, como Norte da África, América do Norte e América do Sul, além de alguns países da Ásia (ALBIN e VILAMIL, 2003).

A colonização espanhola levou as oliveiras para as Américas. No século XVIII, foi introduzida no México, no Peru, no Chile, na Argentina, nos Estados Unidos (Califórnia), na Jamaica e na Austrália. Mais recentemente, foi introduzida também no Japão, na África do Sul, no Uruguai e no Brasil (WREGE et al., 2009; COUTINHO et al., 2009).

O Brasil é um dos maiores importadores mundiais de azeite, pois está entre os maiores consumidores e tem uma área de plantio insignificante, apresentando condições marginais para o cultivo. Atualmente, existe o interesse pelo plantio em alguns estados, entre os quais: Rio Grande do Sul, Minas Gerais, São Paulo e Santa Catarina (COUTINHO e JORGE, 2014).

A oliveira é cultivada normalmente em regiões semiáridas do mediterrâneo, caracterizadas por apresentarem baixa pluviosidade, principalmente no verão, época mais seca da região (chove, em média, 250-550 $\mathrm{mm}$ no período) (WREGE et al., 2009; COUTINHO, 2007). No clima mediterrâneo, durante o inverno, ocorre acumulação de frio, considerado indispensável para o florescimento uniforme, com reflexos positivos no tamanho e na qualidade dos frutos. O frio estimula a formação de compostos bioquímicos e a concentração de hormônios que favorecem a brotação das gemas vegetativas e floríferas (ALMEIDA e ANTUNES, 2012). A temperatura base, que serve de referência para ocorrer o acúmulo de frio na oliveira, é de $12,5{ }^{\circ} \mathrm{C}$ 
(TAPIA et al., 2003). O desenvolvimento vegetativo da planta torna-se lento ou até mesmo paralisa quando as temperaturas permanecem abaixo deste valor.

Embora tenha necessidade de acúmulo de frio no inverno, a oliveira é mais sensível ao frio que outras espécies frutíferas criófilas, ocorrendo um aumento gradual de tolerância com as baixas temperaturas do outono, quando a planta começa a entrar em processo de dormência. Assim, resiste a temperaturas pouco inferiores a $0{ }^{\circ} \mathrm{C}$. Com temperaturas mais baixas que $0{ }^{\circ} \mathrm{C}$, podem ocorrer lesões pequenas nos brotos e nos ramos e, abaixo de $-5{ }^{\circ} \mathrm{C}$, podem ocorrer danos definitivos, e a planta pode morrer quando a temperatura permanecer abaixo de $-10^{\circ} \mathrm{C}$ (NAVARRO e PARRA, 2008).

$\mathrm{Na}$ fase de frutificação, as condições normais de temperatura do ar devem ser de $25{ }^{\circ} \mathrm{C}$ a $35^{\circ} \mathrm{C}$. As plantas, no entanto, são capazes de suportar temperaturas elevadas no verão, próximas aos $40^{\circ} \mathrm{C}$, sem ocorrência de queimaduras nos ramos e nas folhas. Contudo, a atividade fotossintética pode ser inibida quando a temperatura do ar permanecer acima de $35^{\circ} \mathrm{C}$ (COUTINHO et al., 2007).

A necessidade de água, em média, é de 650-800 $\mathrm{mm}$ por ano, de preferência com distribuição regular das chuvas (WREGE et al., 2009; COUTINHO et al., 2007; ALBIÑANA, 2002).

A viabilidade do estigma pode ser comprometida, principalmente se a umidade do ar ficar abaixo de 50\%. Nesta situação, o estigma pode durar menos de três dias, tempo insuficiente para formar o tubo polínico e, assim, formar e fixar o fruto. Por outro lado, se a umidade relativa for muito elevada, próxima de $100 \%$, ocorre a hidratação do grão de pólen, que aumenta de peso e não pode ser levado a uma longa distância pelo vento. Existe ainda a possibilidade do grão de pólen ser destruído devido ao excesso de hidratação (TAPIA et al., 2003). Assim, a umidade relativa do ar ideal deve permanecer entre 60-80\%.

Na primavera, quando ocorre o florescimento, as chuvas não devem ser muito frequentes, para que o grão de pólen não seja lavado do estigma, o que pode reduzir a frutificação efetiva. Nas fases de pré-maturação e maturação dos frutos (final do verão e outono) as chuvas também não devem ser muito intensas, para que o fruto não fique excessivamente aguado, o que dificulta e encarece a extração do azeite, além de deixar a extração mais lenta. Isto pode, também, reduzir a estabilidade do óleo e favorecer a ocorrência de antracnose nos frutos (Gloeosporium olivae), com alterações nas propriedades físicas e químicas do azeite (ALBA, 2004).

Portanto, o estudo e a definição do clima em que a oliveira é normalmente cultivada é fundamental para auxiliar na expansão da cultura pelo mundo e, inclusive auxiliar na escolha da zonas favoráveis para o plantio no Brasil.

O agrupamento das regiões climaticamente homogêneas no mundo para produção de oliveira deve ser feito segundo critérios de similaridade (KELLER FILHO et al., 2005). A análise de agrupamento considera um conjunto inicial de objetos, onde são associadas medidas de várias grandezas denominadas variáveis classificatórias, utilizadas para se obter grupos de objetos assemelhados em relação aos valores assumidos por essas variáveis (KELLER FILHO et al., 2005; EVERRITT, 1993).

Vários trabalhos foram publicados sobre análise hierárquica de agrupamento, definindo regiões climaticamente homogêneas, como os de KELLER FILHO et al. (2005), Diniz et al. (2003), FRITZSONS et al. (2010) e RIBEIRO et al. (2011). 
O objetivo desse trabalho foi identificar grupos de regiões com padrões climáticos similares e, através disso, identificar regiões homogêneas de produção de oliveira no mundo, contribuindo, assim, para estudos que possibilitem o conhecimento das condições naturais de desenvolvimento desta espécie e, com isso, facilitar a indicação de novas áreas para novos plantios em outras regiões, fora das regiões produtoras tradicionais, principalmente no Brasil.

\section{MATERIAL E MÉtodos}

Foram usados dados climáticos do WorldClim, que é uma base de dados climáticos elaborada em nível mundial, a qual permite relacionar espacialmente os locais de ocorrência de oliveiras com dados climáticos. A escolha de uma base de dados mundiais se deu em função dos principais pontos de ocorrência de oliveiras ocorrerem entre os paralelos 30 e $45^{\circ} \mathrm{N}$ e 30 e $45^{\circ} \mathrm{S}$, extrapolando portanto os limites do Brasil.

Foram usadas médias estacionais das temperaturas mínimas e máximas do ar e médias estacionais dos totais de precipitação pluvial, variáveis climáticas relacionadas com a ocorrência da oliveira.

Os dados foram georreferenciados com latitude e longitude (em graus decimais e valores negativos para o hemisfério Sul e valores positivos para o hemisfério Norte, no caso da latitude e, em graus decimais e valores negativos para os meridianos situados a Oeste de Greenwich e valores positivos para os meridianos situados a Leste de Greenwich, no caso da longitude - por convenção) e altitude (em metros sobre o nível do mar) para gerar uma equação de regressão linear simples, permitindo assim que as variáveis de temperatura fossem calculadas em função da latitude, da longitude e da altitude em qualquer ponto georreferenciado da Terra (WREGE et al., 2011; PINTO et al., 1972; ROBERTSON e RUSSELO, 1968).

Foram identificados os locais das regiões de produção de oliveiras em todo o mundo e de algumas regiões com potencial para produção no Brasil, referenciando os dados com coordenadas geográficas latitude, longitude e altitude, totalizando 346 regiões diferentes, localizadas na Europa, Américas do Norte e do Sul e Austrália, além de algumas regiões no Brasil (162 regiões).

Como inicialmente não havia valores de altitude para cada ponto georreferenciado dessas regiões, os dados foram obtidos cruzando-se, em sistema geográfico de informação (SIG), as informações das coordenadas geográficas (latitude e longitude) com o modelo GTOPO30, que contém os valores digitais de elevação de toda a Terra. Esse modelo tem escala 1:250.000, contendo valores extrapolados de altitude a cada 30 metros, na média (USGS, 1999).

Usando-se as coordenadas geográficas em conjunto com as altitudes obtidas nesse modelo, foi possível calcular, para cada região de ocorrência de oliveira e para as regiões com potencial no Brasil, os valores estacionais das temperaturas, usando a regressão linear múltipla, que calcula a temperatura do ar em função da altitude, da latitude e da longitude.

No caso da pluviosidade, foram primeiramente feitos mapas mundiais em SIG para cada estação do ano, usando krigagem por indicação, técnica de geoestatística. Os pontos georreferenciados de ocorrência de oliveiras foram usados para extrair os valores de pluviosidade dos mapas, usando o programa ArcGIS. Realizou-se a extração dos valores de pluviosidade dessa forma, porque 
a mesma não apresenta relação direta com a altitude e com as coordenadas geográficas latitude e longitude, como ocorre com a temperatura do ar.

As informações obtidas pelos dois procedimentos distintos citados anteriormente referentes às temperaturas mínimas e máximas do ar e de pluviosidade acumulada, foram reunidas para cada estação do ano e para cada um dos 346 locais onde ocorrem plantios de oliveiras no mundo, mais os 162 locais com potencial para cultivo no Brasil.

Os dados foram reunidos por região, reduzindo de 346 locais para 71 regiões, visando facilitar a interpretação dos resultados da análise de agrupamento, e foram calculadas as médias dos locais que compunham cada região. Da mesma forma, ocorreu com os dados do Brasil, reunindo as informações por estado.

Fez-se duas análises distintas de agrupamento, a primeira com todos os dados do mundo onde é produzida a oliveira, a segunda reunindo os grupos formados na primeira análise com as regiões que têm potencial para produção de oliveira no Brasil, a fim de verificar se os agrupamentos formados na primeira análise se compõem com as regiões que têm potencial para produção de oliveira no país.

A fim de determinar as zonas homogêneas, em um primeiro passo, definiram-se as variáveis classificatórias, usadas na análise de agrupamento (método de Ward's, 1963). A partir daí, determinou-se o número de grupos para a divisão das variáveis, que foram utilizados na aplicação do método de agrupamento não hierárquico.

A análise de agrupamento desdobrou-se em quatro etapas: a) escolha das variáveis classificatórias, b) especificação de uma medida de similaridade, c) seleção do método de agrupamento e d) decisão quanto ao número de grupos a serem formados, conforme é descrito a seguir:

\section{a) Variáveis classificatórias}

A escolha das variáveis classificatórias reflete 0 julgamento do investigador sobre a relevância das variáveis climáticas, de acordo com os propósitos da pesquisa. Na agricultura, geralmente a temperatura e a pluviosidade são as variáveis mais relevantes, na escala temporal mensal, estacional ou anual. A escala anual não reflete as flutuações sazonais que ocorrem ao longo do ano. Por essa razão, as variáveis classificatórias foram escolhidas de forma a captar as flutuações, na escala estacional. Assim, foram calculados, por estação, os valores médios das temperaturas mínimas e máximas do ar e do total de pluviosidade e feitas as médias estacionais.

Em cada local de plantio no mundo fez-se a caracterização do perfil estatístico dessas variáveis climáticas ao longo de um ano.

\section{b) Medida de similaridade}

É fundamental que, na análise de agrupamento, seja definida uma medida de similaridade ou de distância entre os grupos a serem formados (KELLER FILHO et al., 2005; EVERITT, 1993). Neste caso, foi escolhida a medida métrica Euclidiana, porque as variáveis classificatórias selecionadas são medidas reais.

\section{c) Método de agrupamento}


As variáveis classificatórias foram submetidas ao processo de agrupamento, que objetiva compor grupos com elevada homogeneidade interna, dentro dos grupos, e elevada heterogeneidade externa, entre os grupos.

Com o avanço da tecnologia e do uso da computação, foram desenvolvidos muitos métodos de agrupamento de objetos. Dois deles se distinguem: métodos não hierárquicos e métodos hierárquicos. Os métodos não hierárquicos produzem um número fixo de agrupamentos e os métodos hierárquicos formam agrupamentos por meio de sequência crescente de partições de grupos - abordagem divisiva - ou de junções sucessivas de grupos abordagem aglomerativa.

Não é possível, em princípio, estabelecer o número ideal de agrupamentos para as variáveis selecionadas e, por esse motivo, os métodos hierárquicos aglomerativos são os mais recomendados (KAUFMAN e ROUSSEAU, 1990).

Entre as técnicas de agrupamento hierárquico destacam-se: ligação simples, ligação completa, método centróide, método da mediana, método das médias dos grupos e método da variância mínima (Ward's Method).

Para este trabalho, foi escolhida a técnica da variância mínima (WARD, 1963), recomendado por EDELBROCK (1979). Essa técnica forma grupos de maneira a atingir sempre o menor erro interno entre os vetores que compõem cada grupo e o vetor médio do grupo, o que equivale a buscar o mínimo desvio padrão entre os dados de cada grupo. O resultado pode ser visualizado por meio de um dendrograma.

Com a observação do dendrograma, formado pela técnica da variância mínima, conhecida também como método de Ward, e do gráfico da distância de aglomeração, foi definido o número de grupos, submetido ao método das Kmédias, método mais utilizado quando há muitos objetos a serem agrupados com pequenas variações (SEIDEL et al., 2008).

\section{d) Número de grupos}

A escolha do número de grupos a serem usados baseou-se na análise gráfica do 'Dendrograma' e da 'Distancia de Aglomeração'. Foi calculada a média dos valores das temperaturas mínimas e máximas do ar e a média do total de pluviosidade de cada estação do ano com as estações pertencentes ao mesmo agrupamento, apresentados em gráficos.

\section{RESULTADOS E DISCUSSÃO}

A identificação das zonas climaticamente homogêneas existentes nos diferentes países que exploram comercialmente a cultura da oliveira é importante para conhecer as condições naturais de desenvolvimento da espécie ao redor do mundo. O conhecimento dos padrões climáticos de cada agrupamento formado pode auxiliar na escolha de novos locais para plantio em outros países, incluindo o Brasil (KELLER FILHO et al., 2005).

Os cinco agrupamentos formados na análise são apresentados (Figuras 1 e 2) e descritos a seguir, destacando-se as características que têm em comum. 
Figura 1. Dendrograma formado pela técnica da variância mínima, baseado nas características climáticas das regiões produtoras de oliveiras. O dendrograma apresenta cinco regiões distintas.

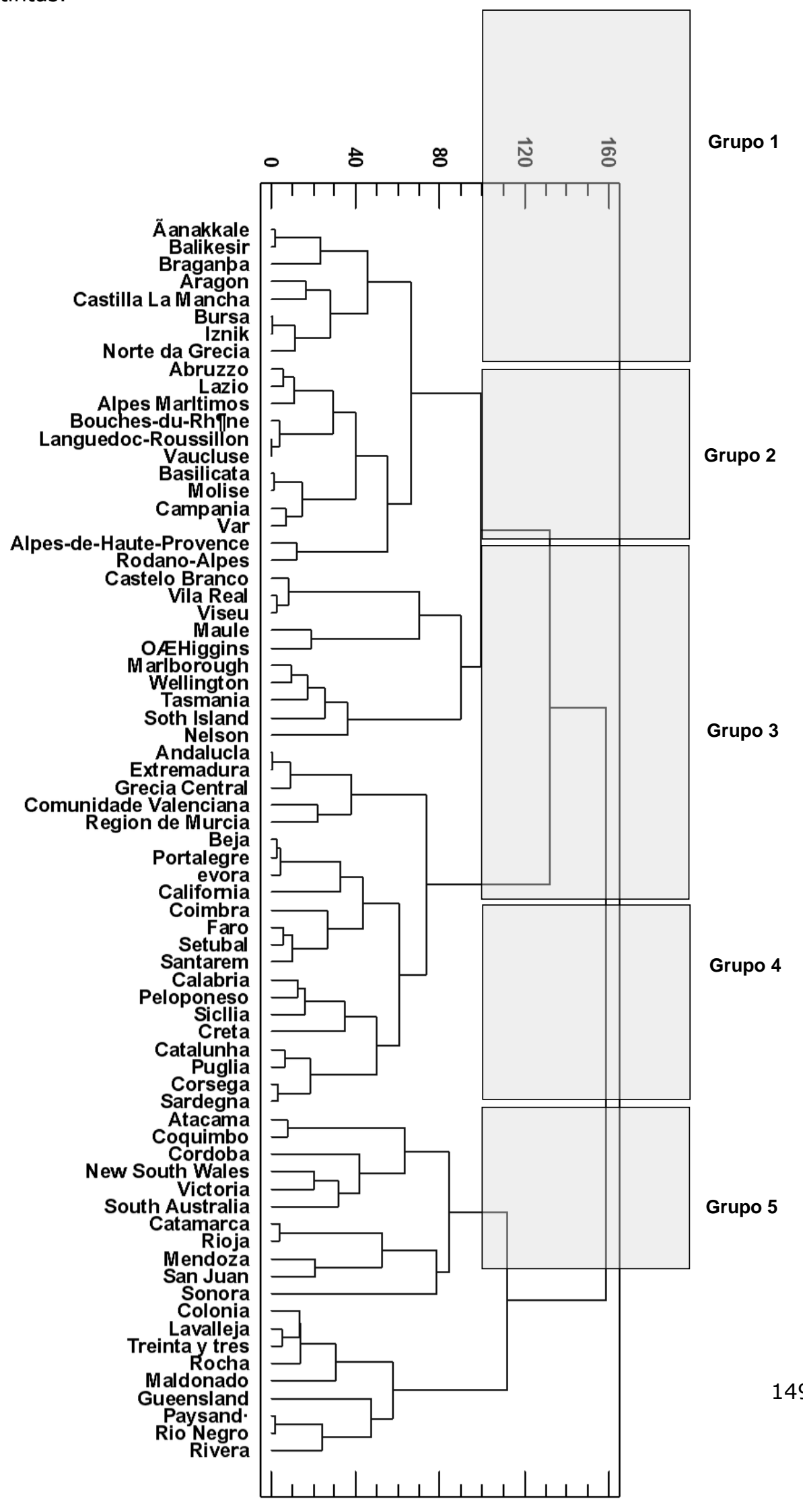


Revista Brasileira de Climatologia

ISSN: 1980-055x (Impressa) 2237-8642 (Eletrônica)

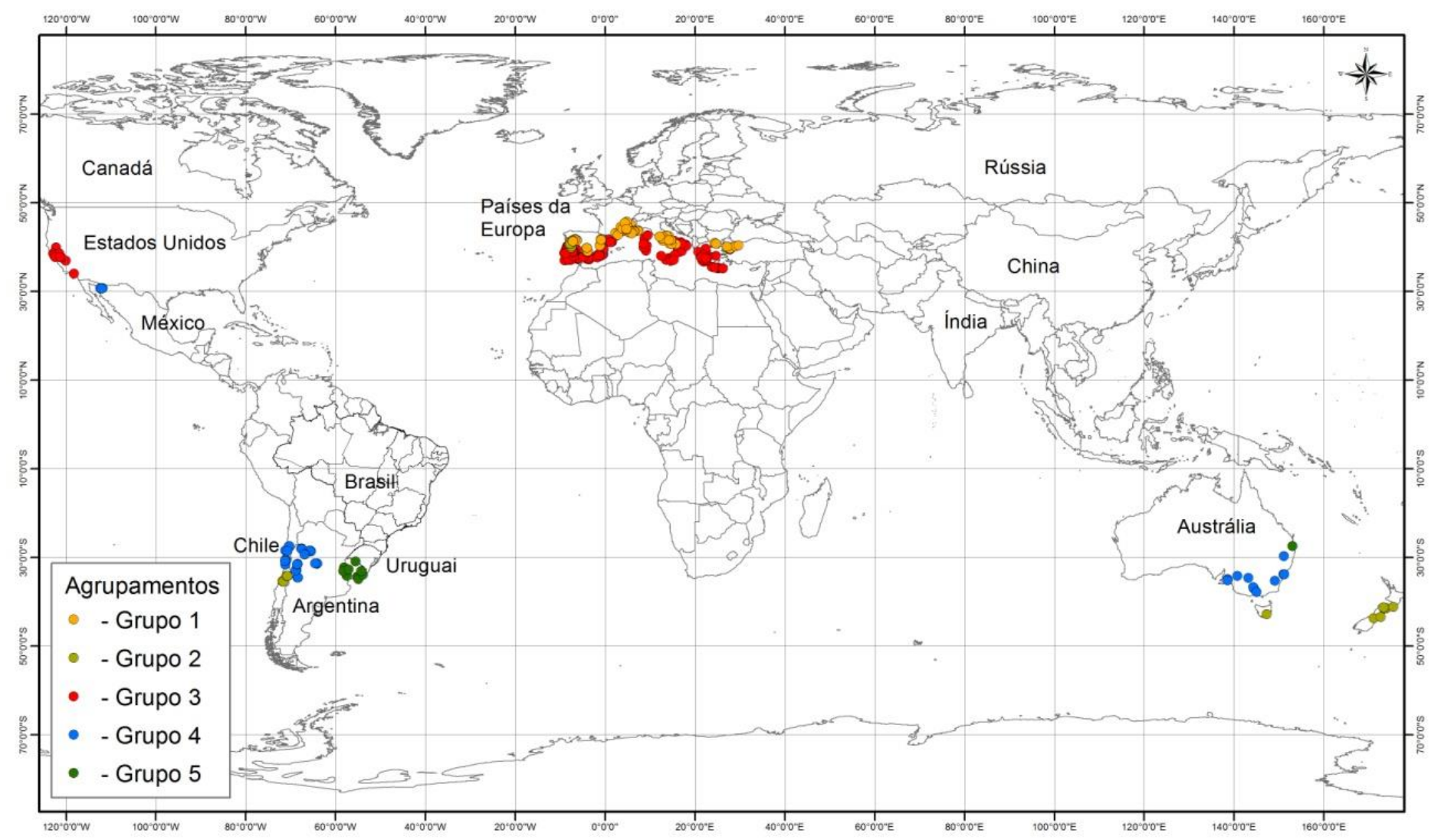

Figura 2. Grupos formados pelas regiões de clima homogêneo no mundo que produzem comercialmente oliveiras, segundo a análise de agrupamento.

Em seguida, são discutidas as características de cada grupo e são feitas comparações com regiões do Brasil (Figuras 3 e 4 e Tabela 1), observando-se semelhanças e diferenças existentes entre os grupos e as regiões no país. 


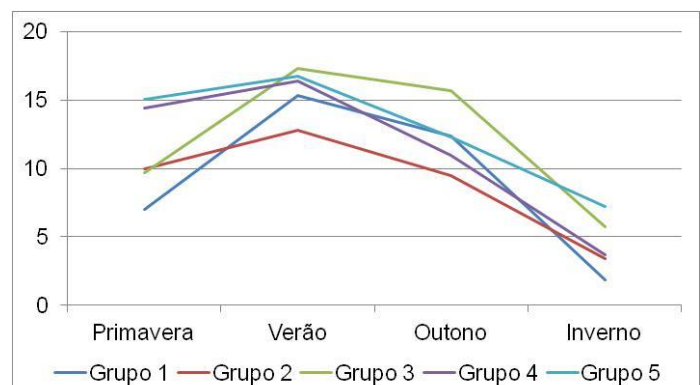

Temperatura mínima $\left({ }^{\circ} \mathrm{C}\right)$

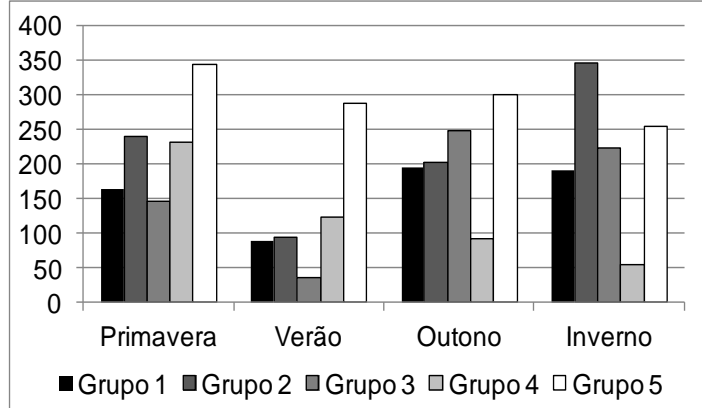

Pluviosidade $(\mathrm{mm})$

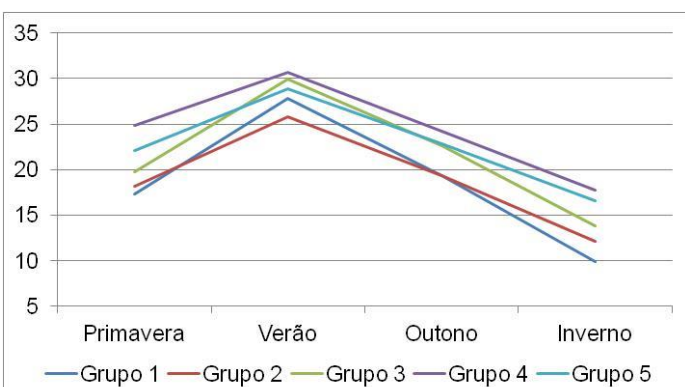

Temperatura máxima $\left({ }^{\circ} \mathrm{C}\right)$

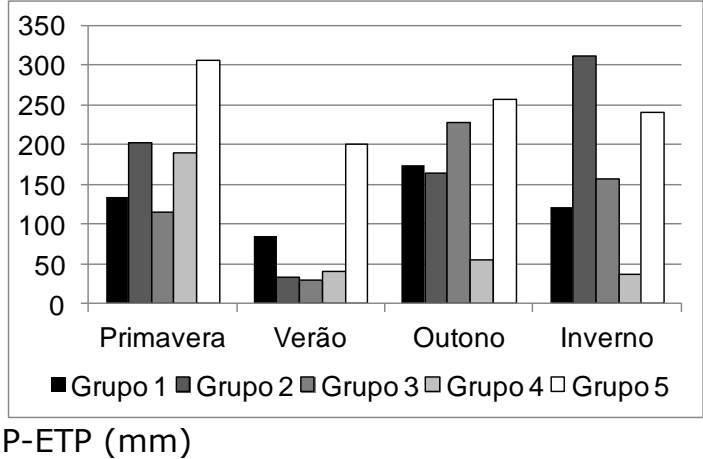

Figura 3. Gráfico das temperaturas mínimas, máximas, da pluviosidade e da diferença entre pluviosidade e evapotranspiração potencial de algumas regiões produtoras de oliveiras no mundo, agrupadas em função das semelhanças climáticas, pela análise de agrupamento.

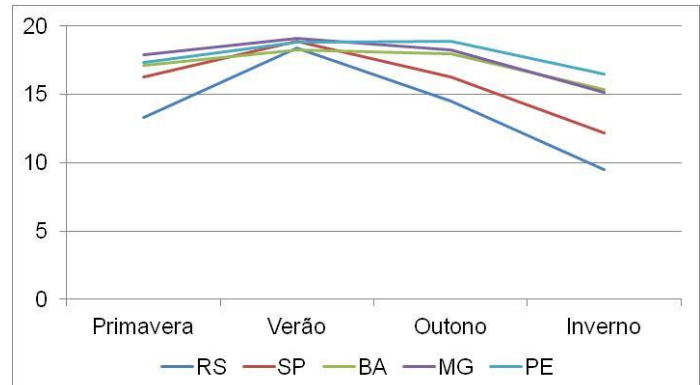

Temperatura mínima $\left({ }^{\circ} \mathrm{C}\right)$

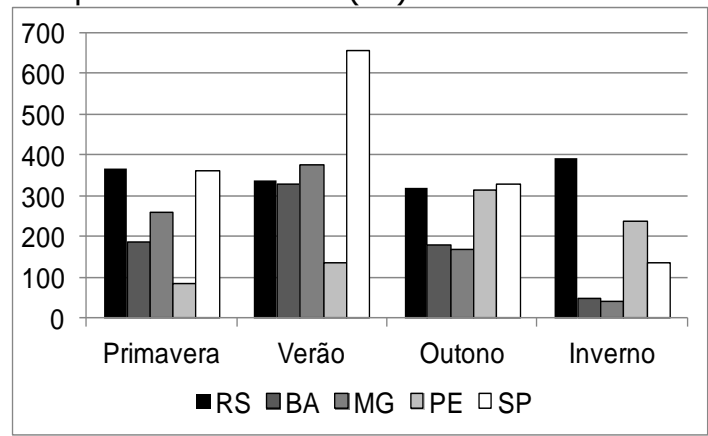

Pluviosidade (mm)

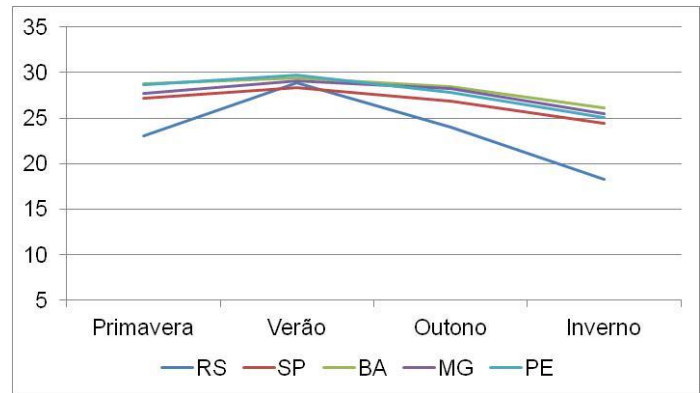

Temperatura máxima $\left({ }^{\circ} \mathrm{C}\right)$

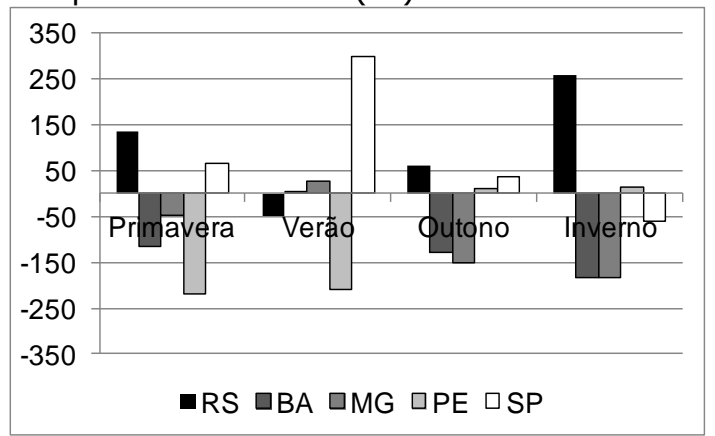

P-ETP $(\mathrm{mm})$

Figura 4. Gráfico das temperaturas mínimas, máximas, da pluviosidade e da diferença entre pluviosidade e evapotranspiração potencial de algumas regiões no Brasil com potencial para cultivo de oliveira, agrupadas em função das semelhanças climáticas, pela análise de agrupamento. RS: Rio Grande do Sul; BA: Bahia; MG: Minas Gerais; PE: Pernambuco e SP: São Paulo. 
Tabela 1. Comparação entre variáveis climáticas dos diferentes grupos formados pela análise de agrupamento e regiões do Brasil.

\begin{tabular}{|c|c|c|c|c|c|c|c|c|c|c|}
\hline estação & $\mathrm{G} 1$ & G2 & G3 & G4 & G5 & $\mathrm{RS}$ & SP & MG & $\mathrm{BA}$ & $\mathrm{PE}$ \\
\hline \multicolumn{11}{|c|}{ Temperatura mínima $\left({ }^{\circ} \mathrm{C}\right)$} \\
\hline primavera & 7,0 & 9,9 & 9,7 & 14,4 & 15,0 & 13,3 & 16,3 & 17,9 & 17,1 & 17,4 \\
\hline verão & 15,3 & 12,8 & 17,3 & 16,4 & 16,8 & 18,4 & 18,9 & 19,1 & 18,3 & 18,8 \\
\hline outono & 12,4 & 9,5 & 15,7 & 10,9 & 12,3 & 14,5 & 16,3 & 18,2 & 18,0 & 18,9 \\
\hline inverno & 1,8 & 3,4 & 5,7 & 3,7 & 7,2 & 9,5 & 12,2 & 15,1 & 15,4 & 16,5 \\
\hline ano & 9,1 & 8,9 & 12,1 & 11,4 & 12,8 & 13,9 & 15,9 & 17,6 & 17,2 & 17,9 \\
\hline \multicolumn{11}{|c|}{ Temperatura máxima $\left({ }^{\circ} \mathrm{C}\right)$} \\
\hline primavera & 17,3 & 18,2 & 19,8 & 24,9 & 22,1 & 23,0 & 27,2 & 27,7 & 28,8 & 28,6 \\
\hline verão & 27,9 & 25,9 & 29,9 & 30,7 & 28,9 & 28,9 & 28,3 & 29,1 & 29,5 & 29,8 \\
\hline outono & 19,3 & 19,3 & 22,6 & 24,2 & 22,8 & 24,1 & 26,9 & 28,2 & 28,5 & 27,8 \\
\hline inverno & 9,9 & 12,1 & 13,8 & 17,8 & 16,6 & 18,3 & 24,4 & 25,5 & 26,1 & 25,1 \\
\hline ano & 18,6 & 18,9 & 21,5 & 24,4 & 22,6 & 23,5 & 26,7 & 27,6 & 28,2 & 27,8 \\
\hline \multicolumn{11}{|c|}{ Pluviosidade (mm) } \\
\hline primavera & 163,8 & 240,5 & 145,9 & 231,3 & 343,6 & 367,0 & 362,8 & 258,9 & 187,2 & 85,2 \\
\hline verão & 89,2 & 93,7 & 37,3 & 123,1 & 288,0 & 338,4 & 656,3 & 377,1 & 330,0 & 135,2 \\
\hline outono & 195,7 & 202,7 & 247,7 & 92,9 & 299,6 & 321,5 & 329,2 & 167,7 & 180,6 & 314,8 \\
\hline inverno & 191,6 & 346,1 & 222,2 & 55,8 & 255,0 & 393,4 & 134,8 & 42,1 & 50,6 & 237,2 \\
\hline ano & 640,3 & 882,9 & 653,2 & 503,0 & 1186,1 & 1426,1 & 1492,8 & 849,0 & 754,7 & 777,1 \\
\hline
\end{tabular}

G1: grupo 1; G2: grupo 2; G3: grupo 3; G4: grupo 4; G5: grupo 5; RS: Rio Grande do Sul; SP: São Paulo; MG: Minas Gerais; BA: Bahia e PE: Pernambuco.

Grupo 1 - Formado pelas localidades situadas na parte Norte do Mediterrâneo, é a região com as menores pluviosidades e temperaturas e onde predomina boa parte das oliveiras cultivadas comercialmente no mundo. Tem as menores temperaturas mínimas no inverno e na primavera, situadas entre 2 e $7{ }^{\circ} \mathrm{C}$, e uma das menores pluviosidades acumuladas no ano, cerca de $640 \mathrm{~mm}$, com período seco no verão, quando chove apenas $90 \mathrm{~mm}$ (Tabela 1). Neste grupo, encontram-se as seguintes regiões ao redor do mundo com registro de cultivo de oliveira: Ãanakkale, Abruzzo, Alpes Marítimos, Alpes-de-Haute-Provence, Aragon, Balikesir, Basilicata, Bouches-du-Rhone, Bragança, Bursa, Campania, Castilla La Mancha, Iznik, Languedoc-Roussillon, Lazio, Molise, Norte da Grécia, Rodano-Alpes, Var e Vaucluse.

Grupo 2 - Neste agrupamento estão os países da América do Sul e Austrália com latitudes similares às da Europa e Estados Unidos, formadas pelo Grupo 3: Argentina, Chile e Austrália. As temperaturas são semelhantes às do grupo 3, de modo geral um pouco inferiores, e as mínimas variam entre $3,4-12,8^{\circ} \mathrm{C}$ e as máximas entre $12,1-25,9^{\circ} \mathrm{C}$, mas a pluviosidade é maior, cerca de $93,7 \mathrm{~mm}$ no verão, a 346,1 mm no inverno. A exceção em relação à pluviosidade ocorre no outono, quando chove $202,7 \mathrm{~mm}$. Tem as menores temperaturas mínimas no verão e no outono, comparando-se com as demais regiões produtoras de oliveira, sendo as mínimas respectivamente de 12,8 e $9,5{ }^{\circ} \mathrm{C}$. Neste grupo encontram-se: Castelo Branco, Marlborough, Maule, Nelson, O'Higgins, Soth Island, Tasmânia, Vila Real, Viseu e Wellington.

Grupo 3 - Esta região é formada pelo agrupamento de vários países do Sul do Mediterrâneo, além de localidades produtoras comerciais de oliveira nos Estados Unidos, situadas na mesma latitude e com as mesmas características de clima. A pluviosidade é um pouco superior à do Grupo 1, $653 \mathrm{~mm}$ em um ano, em contrapartida a $640 \mathrm{~mm}$, onde se concentram as regiões do 
Mediterrâneo situadas mais ao Norte. Somente no outono-inverno a pluviosidade é consideravelmente maior que à do Grupo 1, $470 \mathrm{~mm}$, contra 390 $\mathrm{mm}$ acumulados no período, na média. As temperaturas são um pouco maiores, e a temperatura mínima é, na média, de $5,7{ }^{\circ} \mathrm{C}$ no inverno e a temperatura máxima é de $29,9^{\circ} \mathrm{C}$ no verão, contra $1,8^{\circ} \mathrm{C}$ e $27,9^{\circ} \mathrm{C}$ no grupo 1 . Nesta zona, também estão boa parte das regiões produtoras de oliveira no mundo, entre as quais: Andalúcia, Beja, Calabria, Califórnia, Catalunha, Coimbra, Comunidade Valenciana, Corsega, Creta, Évora, Extremadura, Faro, Grécia Central, Peloponeso, Portalegre, Puglia, Region de Murcia, Santarem, Sardegna, Setubal e Sicília.

Grupo 4 - Neste grupo, estão as regiões produtoras comerciais de oliveira com os menores valores de pluviosidade, situadas entre a Argentina e o Chile, incluindo o Sul da Austrália, em zonas com clima semiárido. O período de maior ocorrência de chuva é o da primavera, com pouco mais de $230 \mathrm{~mm}$ acumulados, e nos demais períodos os valores são consideravelmente baixos, chegando a praticamente $50 \mathrm{~mm}$ acumulados no inverno. É a região com as maiores temperaturas máximas, um pouco superiores a $17^{\circ} \mathrm{C}$ no inverno e 31 ${ }^{\circ} \mathrm{C}$ no verão. As temperaturas mínimas são baixas no inverno, um pouco inferiores a $4{ }^{\circ} \mathrm{C}$ na média, mas, de modo geral, altas nos demais períodos, entre 10-17 ${ }^{\circ} \mathrm{C}$. Neste agrupamento estão: Atacama, Catamarca, Coquimbo, Cordoba, Mendoza, New South Wales, Rioja, San Juan, Sonora, South Australia e Victoria.

Grupo 5 - Esta região é formada pelas localidades produtoras de oliveira situadas basicamente no Uruguai, mas inclui também uma localidade na Austrália, Queensland, na mesma latitude, porém do outro lado do Oceano Atlântico, com características climáticas semelhantes. Comparado-se com os padrões de cultivo de oliveira encontrados em outras regiões do mundo, é a região que apresenta os maiores valores anuais de pluviosidade, cerca de 1200 $\mathrm{mm}$, e com as maiores temperaturas, com mínimas variando de $7,2-16,8{ }^{\circ} \mathrm{C}$ e máximas de $16,6-28,9{ }^{\circ} \mathrm{C}$. De modo geral, na grande maioria dos meses, a pluviosidade é superior aos $280 \mathrm{~mm}$ e as temperaturas mínimas são superiores a $7{ }^{\circ} \mathrm{C}$ e as temperaturas máximas são maiores que $16{ }^{\circ} \mathrm{C}$. As regiões que participam deste grupo são Queensland, na Austrália, e Colonia, Maldonado, Paysandú, Rio Negro, Rivera, Rocha e Treinta y Tres, no Uruguai.

Assemelha-se, de certo modo, com o clima da Metade Sul do Rio Grande do Sul, sendo uma região com pouco mais estiagens e menores temperaturas, comparando-se com essa região do Brasil.

Entre os estados brasileiros, o Rio Grande do Sul apresenta características climáticas mais próximas às do Grupo 5 (região produtora do Uruguai e Queensland, Austrália), com temperaturas mínimas baixas no inverno e máximas elevadas no verão (Figura 5). Algumas regiões do estado de São Paulo também apresentam semelhança, mas a proximidade é menor (Figura 5). Na primavera e no outono, a temperatura no Rio Grande do Sul é intermediária, de forma similar com o que ocorre no Grupo 5. Contudo, as temperaturas são um pouco maiores, de modo geral, e principalmente, o volume de chuvas é maior, concentrando o maior período chuvoso no verão, ao contrário do que ocorre no clima mediterrâneo, onde, neste período, ocorrem os menores volumes de chuva. Na primavera, época de florescimento da oliveira, o volume de chuvas no Rio Grande do Sul chega a quase $350 \mathrm{~mm}$, semelhante ao 
Uruguai, em contraposição aos 150-250 mm do Mediterrâneo. Neste período, é importante que não haja muita chuva, para que não ocorra a lavagem do grão de pólen presente no estigma da flor. No verão, as chuvas acumuladas são também de $350 \mathrm{~mm}$, em contraposição aos 50-100 mm no Mediterrâneo e 300 $\mathrm{mm}$ no Uruguai. Nesse período também não deve haver muita chuva, para que o fruto acumule menos água e a extração do azeite de oliva seja mais fácil, mais rápida e menos onerosa.

No outono, ocorre a maturação dos frutos e, também, o volume de chuvas deve ser baixo. Nas regiões produtoras, chove entre 100 e $250 \mathrm{~mm}$, enquanto que no Rio Grande do Sul chove mais de $300 \mathrm{~mm}$, semelhante ao Uruguai. Portanto, existe a possibilidade de que as cultivares exploradas comercialmente no Uruguai tenham sucesso se forem plantadas no Rio Grande do Sul, devido às semelhanças de clima, principalmente na Metade Sul do Estado (Figura 5).

As regiões de altitude dos estados de Pernambuco, Bahia e Minas Gerais têm semelhanças climáticas (Figura 5). Portanto, as cultivares usadas atualmente no Sul de Minas Gerais poderão ser testadas nestes outros estados, com possibilidade de sucesso. Comparando-se o clima entre os estados (considerando-se as regiões que têm condições de cultivo comercial da oliveira), em Minas Gerias tem-se a menor temperatura no inverno, de $15,1{ }^{\circ} \mathrm{C}$, enquanto na Bahia é de $15,4{ }^{\circ} \mathrm{C}$ e em Pernambuco é de $16,5^{\circ} \mathrm{C}$. A maior temperatura, em Minas Gerais, ocorre no verão, e é de $29,1^{\circ} \mathrm{C}$, enquanto na Bahia é de $29,5^{\circ} \mathrm{C}$ e em Pernambuco é de $29,8^{\circ} \mathrm{C}$. A pluviosidade anual de Minas Gerais é de $850 \mathrm{~mm}$, enquanto na Bahia é de $750 \mathrm{~mm}$ e em Pernambuco é de $780 \mathrm{~mm}$. Em Minas Gerais e na Bahia, os maiores volumes se concentram no verão e os menores no inverno, enquanto que em Pernambuco concentramse mais no outono e são menores no período primavera-verão.

Comparando-se com o clima do Mediterrâneo, as regiões com as maiores altitudes de Pernambuco e da Bahia são, de modo geral, um pouco mais quentes e secas, isto é, em todas as estações do ano, as temperaturas mínimas situam-se entre 15 e $20{ }^{\circ} \mathrm{C}$, e máximas, entre 25 e $30{ }^{\circ} \mathrm{C}$, e são um pouco maiores, se comparadas às da região produtora do Mediterrâneo, com mínimas de $7-15{ }^{\circ} \mathrm{C}$ na primavera, $15-18{ }^{\circ} \mathrm{C}$ no verão, $9,5-12,5{ }^{\circ} \mathrm{C}$ no outono e $1,8-5,7{ }^{\circ} \mathrm{C}$ no inverno e máximas de $17-25^{\circ} \mathrm{C}$ na primavera, $26-31{ }^{\circ} \mathrm{C}$ no verão, $19-24{ }^{\circ} \mathrm{C}$ no outono e, no inverno, $10-18^{\circ} \mathrm{C}$.

Em relação à pluviosidade, na primavera ocorrem de $90-250 \mathrm{~mm}$ nestes estados; No Mediterrâneo é de 150-240 mm; no verão, em Pernambuco e Bahia, é de 140-360 mm; no Mediterrâneo é de 40-120 mm; no outono, em Pernambuco e Bahia, é de 150-300 mm; no Mediterrâneo é de 100-250 mm e, finalmente, no inverno é de 50-250 mm em Pernambuco e na Bahia, contra 50$350 \mathrm{~mm}$ no Mediterrâneo. Portanto, a pluviosidade, no verão, é superior na região Nordeste do Brasil, comparando-se com o Mediterrâneo.

Outras condições são parecidas entre as zonas de altitude dessas regiões do Nordeste brasileiro com o clima Mediterrâneo, exceto o frio no inverno, pois não ocorre acúmulo de frio no inverno nestes estados, como é o caso do Mediterrâneo. As mesmas cultivares plantadas em Minas Gerais podem, de modo geral, ser testadas nas zonas de altitude da Bahia e de Pernambuco, dadas as semelhanças climáticas, entre as quais: Arbequina, Arbosana, Koroneiki e Maria da Fé para azeite e Ascolano e Grappolo, para dupla finalidade, isto é, servem tanto para consumo dos frutos, como para produção de azeite. 


\section{CONCLUSÕES}

As oliveiras são produzidas em torno dos paralelos $30^{\circ}$ nos hemisférios Norte e Sul, estendendo-se entre $30^{\circ}$ e $45^{\circ}$. Nessas faixas de latitude, as características do clima são similares, com temperaturas predominantemente baixas e baixa pluviosidade, principalmente no verão. Próximas deste mesmo paralelo, Queensland (Austrália) e Uruguai, pertencentes ao Grupo 5, são exceções, pois têm valores superiores de pluviosidade e de temperatura mínima do ar.

O clima da parte Sul do Rio Grande do Sul é muito parecido com o clima do Uruguai e de Queensland, na Austrália. Assim, cultivares atualmente plantadas com sucesso provenientes desses dois locais poderão, também, ter sucesso nessa região do Brasil.

O regime pluviométrico da região Nordeste do Brasil se assemelha ao regime do Mediterrâneo, exceto no verão, quando chove mais no Nordeste, na média. A temperatura do ar, nas zonas de altitude do Nordeste do Brasil, é semelhante à temperatura do clima Mediterrâneo no verão, mas é superior nos demais períodos, principalmente no inverno, quando as temperaturas diminuem muito no Mediterrâneo e permanecem as mesmas na região Nordeste.

Os estados da região Nordeste, onde as altitudes são maiores e as temperaturas do ar são mais amenas, têm condições marginais de temperatura e condições favoráveis de pluviosidade para o desenvolvimento da oliveira. Porém, essas regiões não se apresentam com um período de frio definido no outono-inverno, por apresentarem temperaturas mínimas do ar elevadas. 0 período de frio seria necessário para uniformizar o florescimento e favorecer o desenvolvimento de frutos com tamanho e qualidade. Nessas condições, precisam ser testadas ou desenvolvidas cultivares de valor comercial com baixa necessidade de frio ou que não tenham necessidade de frio. 


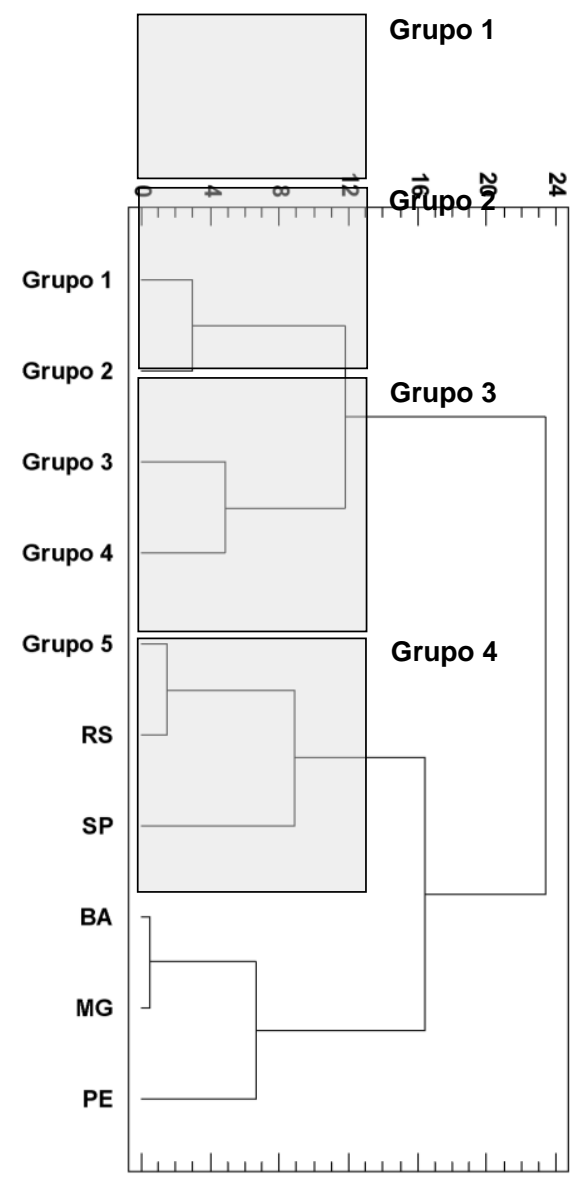

Figura 5. Dendrograma formado pela técnica da variância mínima, baseado nas características climáticas das regiões produtoras de oliveiras e de algumas regiões brasileiras. Grupos 1 a 5: grupos homogêneos formados pelas regiões produtoras de oliveiras no mundo e que têm características climáticas semelhantes. RS: Rio Grande do Sul; SP: São Paulo; BA: Bahia; MG: Minas Gerais e PE: Pernambuco. O dendrograma apresenta quatro regiões distintas. 


\section{REFERÊNCIAS BIBLIOGRÁFICAS}

ALBA, J. Elaboración del aceite de oliva virgen. 6 ed. In: BARRANCO, D., FERNANDEZ-ESCOBAR, R. El cultivo del olivo. Madri: Mundi-Prensa, 2004. p. 615-655.

ALBIÑANA, L. I. Guía completa del cultivo del olivo. Barcelona: Editorial de Vecchi, 2002. 126 p.

ALMEIDA, I.R. de; ANTUNES, L.E.C. Necessidades climáticas e influência do clima sobre adaptação, produção e qualidade. In: ANTUNES e HOFFMANN, 2012. Pequenas Frutas: $\mathbf{5 0 0}$ perguntas, $\mathbf{5 0 0}$ respostas. Você pergunta, a Embrapa responde, p. 41-49. Brasília, 2012.

COUTINHO, E. F.; WREGE, M. S.; REISSER JÚNIOR, C.; ALMEIDA, I. R. de; STEINMETZ, S. Cultivo de oliveira (Olea europaea L.): Clima. Pelotas: Embrapa Clima Temperado, 2009 (Sistema de produção).

COUTINHO, E. F. A cultura da oliveira. Pelotas: Embrapa Clima Temperado, 2007. 143 p.

COUTINHO, E.F. e JORGE, R.O. Olivicultura: Mundo e Brasil. In: FILIPPINI ALBA, J.M.; FLORES, C.A. e WREGE, M.S. Zoneamento edafoclimático da olivicultura para o Rio Grande do Sul. Embrapa, Brasília, 2014. p. 9-10.

DINIZ, G.B. BERLATO, M.A., CLARKE, R. T., FONTANNA, D. C. Identificação de regiões homogêneas de temperaturas máximas e mínimas no Rio Grande do Sul. Revista Brasileira de Agrometeorologia, Santa Maria. V.11, n.2, p. 303-312. 2003.

EDELBROCK, C. Comparing the accuracy of hierarquical clustering algorithms: the problem of classifying everybody. Multivariate Behavior Research, v.14, p.367-384, 1979.

EVERRITT, B.S. Cluster Analysis. $3^{\text {nd }}$ ed. London: Heinemann Educational Books, 1993. $122 \mathrm{p}$.

FRITZSONS, E., MANTOVANI, L., WREGE, M.S. Carta de unidades geoclimáticas para o Estado do Paraná para uso florestal. Pesquisa Florestal Brasileira, 30 out. 2010. Disponível em:

<http://www.cnpf.embrapa.br/pfb/index.php/pfb/article/view/162>. Acesso em: 14 jan. 2011.

KAUFMAN, L. ; ROUSSEAU, W. Finding groups in data: an introduction to cluster analysis. New York: John Willey \& Son, 1990.

KELLER, T.; ASSAD, E.D.; LIMA, P.S. de R. Regiões pluviometricamente homogêneas no Brasil. Pesquisa Agropecuária Brasileira, v.40, n.4, p.311322, 2005.

NAVARRO C., PARRA M. A. Plantación. 6. ed. In: BARRANCO, D., FERNANDEZESCOBAR, R. El cultivo del olivo. Madri: Mundi-Prensa, 2008. p. 188-238.

SANTOS, J.F. El contexto de la olivicultura, la producción y el consumo de aceite da oliva en el mundo. Tesis Doutoral, 2002. p. 295-319.

SEIDEL, E.J.; MOREIRA, JÚNIOR, F.J.; ANSUJ, A.P.; NOAL, M.R.C. Comparação entre o método Ward e o método K-médias no agrupamento de produtores de 
leite. Ciência e Natura, v.30, p. 7-15. 2008. Meio de divulgação: Impresso, Série 1, ISSN/ISBN: 01008307.

TAPIA et al. Manual del cultivo del olivo. La Cerena. INIA, 2003. 128 p. (INIA, Boletin, 101).

U.S. Geological Survey - Survey National Mapping Division. Global $\mathbf{3 0}$ arc second elevation data. 1999. Disponível em:

<http://edcwww.cr.usgs.gov/landdaac/gtopo30/gtopo30.html>. Acesso em: 25 set. 2011.

WARD, J.H. Hierarquical grouping to optimize an objective function. Journal of the American Statistical Association, v.58, p.236-244, 1963.

WREGE, M. S.; COUTINHO, E. F.; STEINMETZ, S.; REISSER JUNIOR, C. ; ALMEIDA, I. R. de ; MATZENAUER, R. ; RADIN, B. . Zoneamento Agroclimático para Oliveira no Estado do Rio Grande do Sul. Pelotas: Embrapa Clima Temperado, 2009 (Documentos).

WREGE, M.S.; STEINMETZ, S.; REISSER JR, C.; ALMEIDA, I.R. Atlas Climático da Região Sul do Brasil: Estados do Paraná, Santa Catarina e Rio Grande do Sul. Pelotas: Embrapa Clima Temperado; Colombo: Embrapa Florestas, 2011. 336 p.

Texto submetido à RBClima na data de 10/03/2015 